\title{
Analysis of Mobile Phone Live Era of Ideological and Political Education Opportunities and Challenges in Higher Vocational Education
}

\author{
Xiao Huimin \\ Shandong Labor Vocational and Technical College, Ji'nan City, Shandong province 250022
}

Keywords: mobile phone live era; ideological and political education; opportunities and challenges

\begin{abstract}
Century, with the rapid development of mobile phone media, mobile phone has become the people's daily necessities, mobile phone is not only responsible for communication equipment used, it is a small window to understand the world, and all kinds of mobile phone software on the live a lot of people's favorite, which brings a lot of opportunity for Higher Vocational Ideological Education, but also brought many challenges in all aspects. Starting from the features of mobile phone broadcast software, the new educational ideas in-depth study of live era has brought to the ideological education in Higher Vocational Education and the new ideas, and can bring good use of live time convenience, break the old form of education.
\end{abstract}

\section{Introduction}

Mobile phone into the era of live experience, new way of education, the use of mobile phone can live at any time, any place at any time to know the latest news and information, greatly improving the speed of information dissemination, faster and more accurate access to the latest educational resources. Transfer students from the past one-way absorption of teacher information, to many aspects now have new knowledge, the relationship between teachers and students tended to be equal, to some extent, enhance the ideological and political education teaching level, improve the teaching quality of Ideological and political education, it is a breakthrough of the teaching method.

\section{The mobile phone live features}

The spread of mobile broadcast software is for the public, the threshold is low, everyone can participate in it, everyone can live broadcast. You can find the latest news anytime and anywhere, and you can find articles, videos, pictures and so on according to your own preferences. Diversified forms, in line with the needs of the public. It is because of its openness and rich network forms, which led to the "keyboard man" and many network garbage, network violence and other phenomena [1].

With the arrival of the era of mobile phone broadcast, mobile phone watch live, also gradually sought after by many people, many college students will also learn to relax as pressure pastime tools, mobile phone and broadcast communication is established on the basis of interpersonal communication with strangers, the two parties can speak freely, without communication, although this is a lot of vocational college students decompression platform, but also learned a lot of negative information is not conducive to the socialist core values.

Nowadays, many people use mobile phone live to make money in the mobile phone broadcast software, can use real money to buy virtual "cruise" "Lamborghini" "Lollipop" gift to give love network anchor, which has become a network anchor tool to make money. Many college students to seize this money, will have to follow, the webcast will be used to make money, to learn a lot of time to do network anchor, the desire for money to increase, so no learning. But for students who watch mobile phone broadcast, they may spend a lot of cash to buy virtual gifts to their favorite network anchor, it will not only delay the study, abandoned their studies, but also to some students bring some pressure on the economy [2]. 


\section{Mobile phone broadcast era has brought to the ideological and political education opportunities}

The arrival of the era of mobile broadcast, the past by teachers preaching, book delivery and text description of the teaching forms to enrich, to the image, video, sound and animation channels for information transmission. For example: during the teaching of poetry, teachers can play the poetry audio, let the student feel the author reading methods and poems in cadence expression of human feelings. Such a form of teaching has greatly enriched the past single teaching form, but also can stimulate the enthusiasm of students in the classroom, and interest in learning. This provides favorable conditions for ideological and political education in higher vocational colleges, broadens the form of education in the form of new media, enriches the ways for students to accept information knowledge, and thus improves the quality of teaching [3].

Schools can use new media mobile phone broadcast software to carry out campus activities, such as sports class, teachers can through the large screen broadcast gymnastics teaching video, let the students follow the characters in the video to learn the essentials of gymnastics. This will not only improve the teaching progress, but also because of the music effect in the video and enhance the atmosphere of the classroom. The use of new media to teach, in the premise of enriching the campus culture, but also stimulate the enthusiasm of students to participate in activities, improve the all-round development of moral, intellectual, physical, aesthetic and labor. To improve the students' Ideological and moral qualities and scientific and cultural qualities.

In the development of campus cultural activities, to the ideological and political education into cultural activities, such as: mobile phone broadcast software through learning the party's principles and policies, and implement the spirit of the party's nineteen party will be comprehensive, integrated with the advanced concept of Ideological and political education, enhance the teaching results. In the new media era, the university campus is also advancing with the abundant information carrier, such as WeChat or QQ group through the letter, notice in the form of important information and propaganda and cultural activities, thus promoting the development of campus culture, provides a good platform for the ideological and political education for students.

The traditional way of teaching confined to the classroom teaching, the emergence of new media, enrich the ways of Ideological and political education in college, teachers and students can not limited by time and place, through the new media to teach the ideological and political education. For example: some students due to sick leave or leave to come to school, then the students can live through the new media mobile phone by way of lectures, so that not only will not delay the immediate things, will not delay the course. If a student wants to broaden their knowledge, so in the network to download the relevant instructional videos, such learning content will not be accepted class restrictions, to promote the role to improve the students' Ideological and political education play [4].

\section{Mobile phone broadcast era of Higher Vocational Ideological and political education challenge}

The new media broadcast mobile phone software to enrich people's vision, can understand to the thousands of miles of news fun, entertainment, beauty and delicacy of geography, even immediately happened through the mobile phone live the way to everyone. While people are enjoying a new era of high technology brings convenience to people, the disadvantage is quietly. Because the mobile phone broadcast platform threshold is low, all people can live as long as the registered account, so there are some malicious speculation network anchor, and even many businesses will therefore use the form of live to seek personal interests. Because of the higher vocational students are in the outlook on life and values formation and establishment of the period, the emergence of these phenomena, to a certain extent to the higher vocational students' physical and mental development have a negative impact, easy to make them have ideological bias, hindered the direction of Ideological and political education. 
The form of teaching methods of traditional ideological and political education is single, it is difficult to stimulate students' interest in learning, and mobile phone broadcast software has the richness and diversity is very strong, anyone can use mobile phone software whenever and wherever possible live information, and students often curiosity, the way of information transmission, greatly satisfy the students curiosity and interest. This is just let some criminals seize the mentality of such students, using mobile phone live software hype content inconsistent with the mainstream value. But because the mobile phone software on the visual impact of live students is much higher than the effect of literal communication for students. So, the rich information broadcast mobile phone to the traditional ideological and political education is a challenge.

In traditional teaching, most teachers are teaching according to the fixed, the original teaching content, single form and content limitation, and mobile phone broadcast information in software has diversity and timeliness, to meet the students of the unknown curiosity, but also for students to seek knowledge in hand to provide more choices. The changing of information and knowledge, is a great challenge to the higher education workers, to appear in the classroom the students are unwilling to listen to the teacher, and can not start the phenomenon, plays a key role in the ideological and political education on the road.

Mobile phone software live rich and intuitive, get a lot of students, many students regard it as the decompression platform, but there are also many students addicted to mobile phone live webcast, facing to their "high" interests and through mobile phone inner pressure relief live easily, various causes the students are immersed in the network world, and neglect their studies. In order to better ideological and political education, teachers should first save these students from the network, which often takes a lot of time and effort. So, it is a challenge in the learning of higher vocational students on the road [5].

\section{Improve the ideological and political education of Higher Vocational Students' suggestions}

In the new media broadcast mobile phone era, the school should strengthen the effectiveness of Ideological and political education of the students, in the mobile phone media, to strengthen the relevant laws and regulations, such as: the development of "on the standard use of network communication regulations", take the real name system for mobile phone use live broadcast, improve mobile phone the threshold, to prohibit any person wantonly spread bad information. Because the mobile phone software system wide spread widely jumbled, processing is not simple, plus the lack of this kind of phenomenon of specialized laws and regulations and supervision system of the specific network environment, leading to different "barren", also hope that the relevant departments of the state for the mobile phone software can live as soon as possible to sort out the authority of laws and regulations to strengthen the system of the most specific. The pace and intensity, improve network quality, provide a good network environment for students.

In the mobile phone broadcast software increases the "filter", such as: some people spread bad information in mobile phone media, the system will automatically for the first time, these bad information devour, to avoid the spread of harmful information, increase network energy, resist the bad information.

Make full use of the advantages of the rapid spread of mobile phone, increase the content of Ideological and political education. Such as: reduce the advertising content on the network "small window", replace it into Ideological and political education information, build a good campus culture, eliminate the negative impact of mobile phone live broadcast to students.

Enrich the ideological and political education of vocational students, break the routine preaching way, and develop the innovative education system that students like and adapt to the contemporary students. Such as: open seminars, debates, prepare relevant questionnaires, organize the implementation of campus cultural activities, to enrich the ideological and political education, improve the students' awareness of the ideological and political education, to promote the accuracy of Ideological and cultural communication, enhance the quality of education [6].

The ideological and political education is a long process of education, colleges and universities should actively strengthen teachers, improve the education system, the ideological and political 
aspects should be targeted for education, the students do not make a perfect education act with undue haste. In the aspect of education to "the times", keep pace with the times, timely understanding of the students' psychological tendency, should not only have professional ideological and political core, but also proficient in mobile phone live media technology, the traditional education system and mobile phone media full combination of teaching, teachers and students to achieve the desired effect of teaching in Higher Vocational Colleges interest in the study of Ideological and political education, enhance the effectiveness of Ideological and political education.

To guide the students to use mobile phone broadcast software, strengthen students' sense of responsibility, consciously abide by the relevant laws and regulations, in accordance with the provisions of the use of mobile phone software is live, consciously resist and not arbitrarily spread bad information, self education and self restraint, know what to do and what not to do, and jointly create a good network environment.

\section{Conclusion}

With the continuous development of mobile phone broadcast era, Higher Vocational Ideological and political education workers should keep up with the development of the times, the times, according to the characteristics of vocational students, develop and combine the new era of teaching facilities to make full use of mobile phone products, broadcast software, enrich the traditional ideological and political education, change the teaching style, innovative forms of education a reasonable guide, students on Ideological and political learning, consciously resist the bad information, to realize the innovation of education system by using the mobile phone new media, to cultivate high-quality talents of high quality, new.

\section{References}

[1] Liu D F. An Analysis of Ideological and Political Education Innovation in Higher Vocational Colleges from the Perspective of School-enterprise Cooperation[J]. Jiangsu Education Research, 2014.

[2] Liu P. Opportunities and Challenges of the Ideological and Political Education for College Students in New Era[C]// 2015 international conference on economics, management, law and education. 2015.

[3] Xiong P A. Opportunities and Challenges of Ideological and Political Education of College Students in Microblog Era[J]. Journal of Hubei University of Education, 2013.

[4] Lin W, University F N. Opportunities and Challenges: A Study of Ideological and Political Education in Colleges and Universities in the Context of Big Data[J]. Journal of Shijiazhuang Tiedao University, 2017.

[5] Bai N. Exploration of Ideological and Political Education in Higher Vocational Colleges Under the Background of New Media[J]. Shipbuilding Vocational Education, 2016.

[6] Hu X. On the Innovation of Ideological and Political Education in Higher Vocational Colleges in the New Media Era[J]. Science Education Article Collects, 2017.

Xiao Huimin (1979.7-), female, Han nationality, Shandong Jinan, lecturer, master, mainly engaged in the research of Ideological and Political Education 